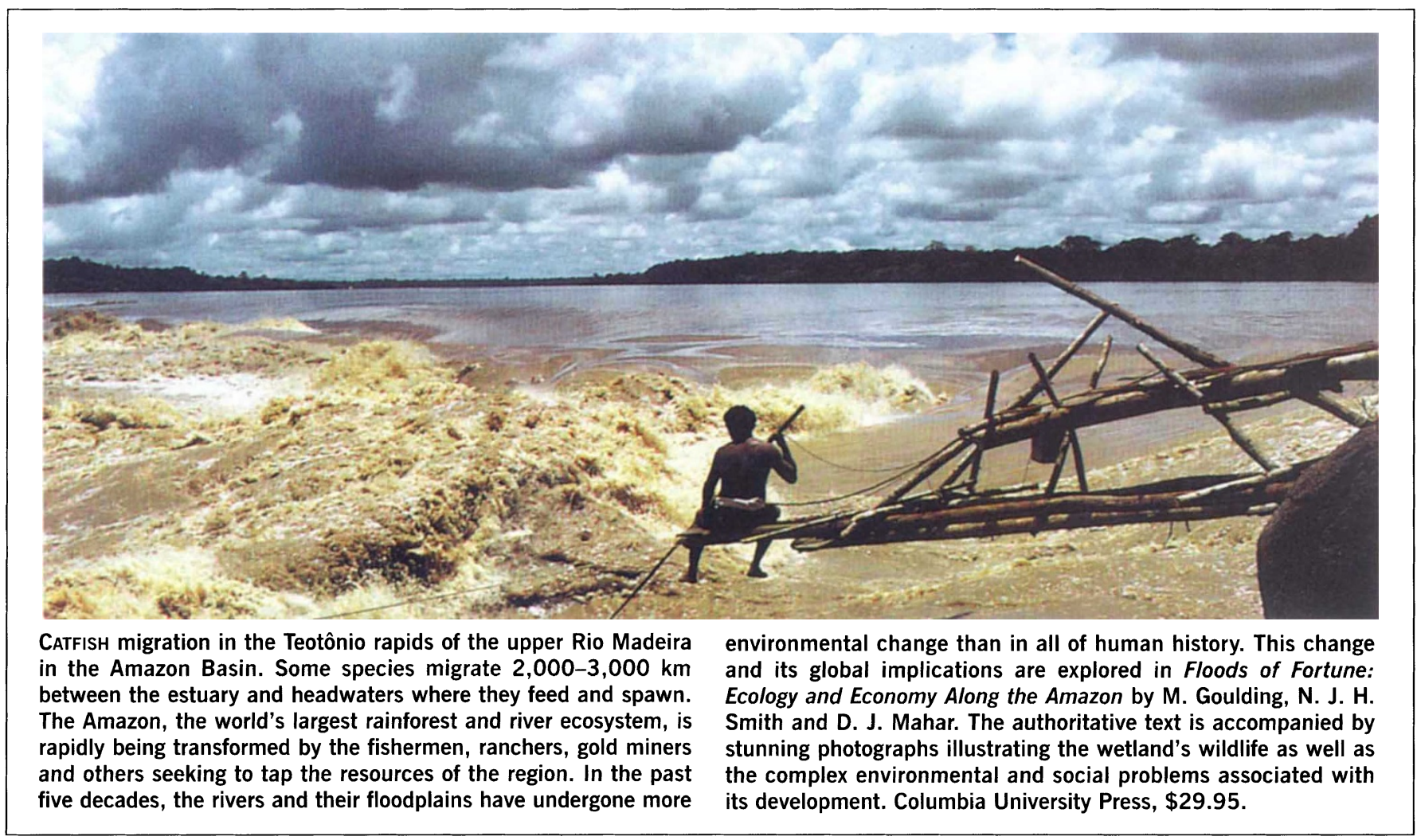

\section{To coldly go}

\author{
John Haslett
}

Arctic and Alpine Biodiversity: Patterns, Causes and Ecosystem Consequences. Edited by F. S. Chapin III and C. Körner. Springer: 1995. Pp. 332. DM198, $£ 92.50, \$ 143$

"LIFE in the Freezer", a recent television series about Antarctic organisms, showed some of the more spectacular aspects of nature under the extreme conditions of cold and desiccation. Predictably, it mainly featured penguins, seals and whales, no doubt because of their aesthetic appeal. But because penguins are found only in the Southern Hemisphere, and seals and whales are not generally found on mountains, the editors of this book on organisms in similarly inhospitable arctic and alpine environments were faced with a formidable task in attracting a wide audience, albeit within scientific circles. The bait they have used is the theme of 'biodiversity', which serves as the framework for the book. The approach is both appropriate and useful.

Biodiversity is more than simply a measure of the number of species; it describes the variety of life over a wide spectrum of levels, from genetics through the taxonomic and ecological hierarchies to communities, habitats and ecosystems. Human activity is causing serious destruction of biodiversity at all of these levels. As our awareness of the problem has increased, two main areas of concern have become apparent. The first is that we are losing biodiversity faster than science can catalogue it, so attention is centred on tropical 'hotspots' - regions extremely rich in species, many of which remain undescribed. In this way, biodiversity has become synonymous with (tropical) species richness, but that area is only part of the story. The second area of concern, and the one that provides the book's focus, is ecosystem function: if we lose variety within a system, will the system be able to keep going in a similar way? Here the idea of 'keystone' species (or other functional ecological units) becomes important, but their identification requires knowledge of the patterns and causes of the present biodiversity of the ecosystem.

Arctic and alpine ecosystems are characteristically low in species, to the extent that they are often referred to (incorrectly) as 'simple' ecosystems. Yet, like the species-rich tropics, they are also prone to heavy losses in biodiversity through human activity. The book serves as a timely reminder of this vulnerability.

Chapters provide a basis for discussion of arctic and alpine biodiversity at all levels, from genetics to ecosystem, although there is clearly some confusion among the authors as to the precise meaning of 'biodiversity'. The three main sections reflect the principal objectives of the editors: description of the patterns and causes of diversity, development of a framework for predicting change and discussion of the results of change. Ambitious indeed; and, viewed in these terms, the book is only partly successful. Although the standard of science is generally high, there is an overall lack of balance in subject matter. More than two-thirds of the contributions are specifically about arctic environments, and a similar proportion are devoted to plants. If, like me, you happen to have an interest in animals on mountains, a single chapter is your lot. But it is pleasing to find discussion of microbial biodiversity, a topic often neglected by ecologists.

Another difficulty is failure to take proper account of the differences between artic and alpine ecosystems. Alpine environments are extremely varied over a wide range of spatial scales, with correspondingly complicated ecological dynamics. This makes them unique. So it is wrong, as has traditionally been the case, to lump 'alpine' environments with 'arctic' environments simply because they are both extremely cold. It is also wrong to attempt to extrapolate across the arctic-alpine divide when there are no good grounds for doing so, a temptation even the editors cannot resist in their final summary chapter.

Nevertheless, the book is important: appreciation of biodiversity in habitats characteristically low in species is crucial to our understanding of the global biodiversity 'crisis'. But before we can think of predicting and discussing the consequences of change in biodiversity, we need to think more about the differences between ecosystems, not just their similarities.

John Haslett is at the Zoologisches Institut, Universität Salzburg, Hellbrunnerstrasse 34, A-5020 Salzburg, Austria. 